\title{
A numerical study on amplitude characteristics of the terdiurnal tide excited by nonlinear interaction between the diurnal and semidiurnal tides
}

\author{
Chun Ming Huang ${ }^{1,2}$, Shao Dong Zhang ${ }^{1,2}$, and Fan Yi ${ }^{1,2}$ \\ ${ }^{1}$ School of Electronic Information, Wuhan University, Wuhan, Hubei 430079, People's Republic of China \\ ${ }^{2}$ Laboratory of Geospace Environment and Geodesy, Wuhan University, Wuhan, Hubei 430079, People's Republic of China
}

(Received August 23, 2006; Revised November 18, 2006; Accepted December 4, 2006; Online published May 7, 2007)

\begin{abstract}
A fully nonlinear numerical tidal model has been developed with the aim of presenting amplitude features of the terdiurnal tide excited by nonlinear interaction between the diurnal and semidiurnal tides. Since the superposition of the migrating diurnal and semidiurnal tidal solutions from the GSWM-00 (Global Scale Wave Model 2000) is taken as the initial disturbance for this nonlinear model, the diurnal and semidiurnal tides are allowed to nonlinearly interact with each other. The analyses on the simulations show that the migrating terdiurnal tide can be significantly excited by the nonlinear interaction between the diurnal and semidiurnal tides in the mesosphere and lower thermosphere (MLT) region, especially above $90 \mathrm{~km}$, and have pronounced amplitudes (wind speeds over $15 \mathrm{~m} \mathrm{~s}^{-1}$ and temperature over $10 \mathrm{~K}$ ) in the lower thermosphere $(90-110 \mathrm{~km})$. In addition, its amplitudes vary strongly with season and maximize during equinoctial months at low and middle latitudes, and its zonal wind component is larger than the meridional wind component. Simultaneously, the diurnal and semidiurnal tides exhibit evident variations, indicating that the wave-wave and wave-mean flow interactions are the important cause of the tidal variability. Our calculations also illustrate the remarkable alteration of the background fields induced by the mean flow/tidal interaction, implying this interaction should be comprehensively considered in describing global atmospheric dynamic and thermal structures in the MLT region.
\end{abstract}

Key words: Middle atmosphere dynamics, waves and tides, general and miscellaneous.

\section{Introduction}

Atmospheric solar tides (hereinafter tides) are globalscale waves with periods that are harmonics of a solar day. They are believed to play an important role in the large-scale circulation patterns and strongly modulate the propagation conditions experienced by upward propagating gravity waves in the mesosphere and lower thermosphere (MLT). By definition, the migrating tides are the subset of tides propagating westward with the apparent motion of the Sun, with zonal wavenumbers $s$ equal to their frequencies $n$ in cycles per day. The migrating tidal components with frequencies $n=1,2,3$ are respectively named the migrating diurnal, semidiurnal and terdiurnal tides.

The diurnal and semidiurnal tides are the most prominent tidal components found in the MLT, but the terdiurnal (8-h) tidal component has been also seen in a number of observations of the MLT (Teitelbaum et al., 1989; Thayaparan, 1997; Taylor et al., 1999; Pendleton et al., 2000; Smith, 2000; Akmaev, 2001; Yi, 2001; Aso, 2003; Batista et al., 2004; Namboothiri et al., 2004; Zhang et al., 2004; Wu et al., 2005), indicating that it is a permanent feature of the horizontal wind and temperature variability there. The amplitude of the terdiurnal tide is generally smaller than that of the diurnal or semidiurnal tide, although on occa-

Copyright (c) The Society of Geomagnetism and Earth, Planetary and Space Sciences (SGEPSS); The Seismological Society of Japan; The Volcanological Society of Japan; The Geodetic Society of Japan; The Japanese Society for Planetary Sciences; TERRAPUB sion it has been found to be comparable (Teitelbaum et al., 1989; Thayaparan, 1997; Taylor et al., 1999; Pendleton et al., 2000; Namboothiri et al., 2004). The terdiurnal tide has also been found to be characterized by significant amplitudes (wind speeds over $20 \mathrm{~m} \mathrm{~s}^{-1}$ and temperature over $15 \mathrm{~K})$ in the lower thermosphere $(90-100 \mathrm{~km})$. However, theoretical treatment of this tide has not received much attention, possibly due to its being the third harmonic component of tides and its high global asymmetry. There may be many kinds of physical processes responsible for the observed terdiurnal tide, including direct generation by solar thermal heating, nonlinear interaction between the diurnal and semidiurnal tides, tidal/gravity wave interaction, changes in excitation sources in the lower atmosphere and mean flow/tidal interaction. The former two are the primary generation mechanisms for the migrating terdiurnal tide, and modeling studies have been carried out by Teitelbaum et al. (1989), Akmaev (2001), and Smith and Ortland (2001). Teitelbaum et al. (1989) simulated a case corresponding to solstice conditions and found that the effective tidal components from the two generation mechanisms were of comparable amplitude. In the model used for that study, the analytical forcing due to tidal interactions had been added by including the second-order (wave-wave interaction) terms calculated from the simulated diurnal and semidiurnal tides into the linearized terdiurnal tidal solutions. In a subsequently investigation based on mediumfrequency $(\mathrm{MF})$ wind measurements over London, Canada 
$\left(43^{\circ} \mathrm{N}, 81^{\circ} \mathrm{W}\right)$, Thayaparan (1997) found that in the MLT region, the wind variability of the 8 -h tide was closely associated with that of the diurnal and semidiurnal tides, implying that the diurnal and semidiurnal tides might interact with each other and that the variability in the 8-h tide to a large extent resulted from such an interaction. Smith and Ortland (2001) successively used the ROSE model and a linear model to study both the thermally and nonlinearly generated terdiurnal modes and found that the latter was the dominant source at low latitudes. Their results were able to reproduce many of the features observed in the UARS HRDI data (Smith, 2000). In this modeling approach, the nonlinearly generated terdiurnal tide was calculated by specifying the diurnal and semidiurnal tidal fields at the lower boundary based on the Global Scale Wave Model (GSWM) results. These values represented the upward extension of the tides generated in the troposphere, possibly modified by interactions occurring above the tropopause in the GSWM. Additionally, an MF observational study at $45.4^{\circ} \mathrm{N}$ by Namboothiri et al. (2004) revealed that the amplitude of the terdiurnal tide displayed evident short-term variability and its large amplitude occurred simultaneously with the large amplitudes of the diurnal and semidiurnal tides, implying that the terdiurnal tide was generated by nonlinear interaction between the diurnal and semidiurnal tides.

It is well known that nonlinear interaction between the migrating diurnal (zonal wavenumber 1) and semidiurnal (zonal wavenumber 2) tides leads to the excitation of the sum (zonal wavenumber 3 , or terdiurnal) and difference (another diurnal component) in the modes. In the investigation reported here, we adopted a method quite different from those adopted by Teitelbaum et al. (1989) and Smith and Ortland (2001) to present a detailed modeling study on the nonlinearly generated terdiurnal tide. In our simulations, a fully nonlinear numerical tidal model is utilized. Moreover, the diurnal and semidiurnal tidal fields are specified in the whole computational region based on the GSWM-00 results, so the interaction between them is entirely ubiquitous. Compared with the modeling work of Teitelbaun et al. (1989), the present work can account for all higher order terms, not only the second-order term. In addition, the self interaction of each tide is calculated, and the significant effects of these on tidal amplitudes have been verified by Huang et al. (2007a, b). The model provides monthly simulation results by adopting a more realistic background atmosphere.

The paper is organized as follows. In the following section, our numerical tidal model, mainly including governing equations, initial values, boundary conditions and processing algorithm, is introduced in detail. Section 3 reports the nonlinear simulation results, namely the excited terdiurnal tidal amplitude, the diurnal and semidiurnal tidal differences regarding to the prescribed values and the background alteration. Sections 4 and 5 are devoted to discussions and conclusions, respectively. For additional technical details of our numerical algorithm, the reader is referred to Huang et al. (2007a).

\section{Numerical Models}

\subsection{Governing equations}

Our nonlinear tidal model is similar to GSWM-00, but the linear assumption, namely tidal fields, are considered to be small perturbations on a basic state, and the hydrostatic assumption are removed. Other basic assumptions of the GSWM-00 are retained: the earth is assumed to be a smooth sphere; the atmosphere is assumed to be a compressible, shallow perfect gas; tidal fields are treated as perturbations on the initial given basic state, that is a purely mean zonal flow dependent only on latitude and altitude; the zonal mean meridional and vertical winds are neglected. Therefore, the Navier Stokes equations can be written as below:

$$
\left\{\begin{array}{l}
\frac{\partial u^{\prime}}{\partial t}+\frac{u_{0}+u^{\prime}}{a \cos \varphi} \frac{\partial u^{\prime}}{\partial \lambda}+\frac{v^{\prime}}{a} \frac{\partial\left(u_{0}+u^{\prime}\right)}{\partial \varphi}+w^{\prime} \frac{\partial\left(u_{0}+u^{\prime}\right)}{\partial r} \\
\quad-\frac{\left(u_{0}+u^{\prime}\right) v^{\prime}}{a} \tan \varphi+\frac{\left(u_{0}+u^{\prime}\right) w^{\prime}}{a}-2 \Omega \sin \varphi v^{\prime} \\
\quad+2 \Omega \cos \varphi w^{\prime}=-\frac{R}{a \cos \varphi}\left(\frac{\partial T^{\prime}}{\partial \lambda}+\frac{T_{0}+T^{\prime}}{\rho_{0}+\rho^{\prime}} \frac{\partial \rho^{\prime}}{\partial \lambda}\right)-D_{\lambda} u^{\prime} \\
\quad+\frac{1}{\rho_{0}} \frac{\partial}{\partial r}\left[\left(\mu_{0}+\rho_{0} v_{e d d y}\right) \frac{\partial u^{\prime}}{\partial r}\right]-v_{R} u^{\prime} \\
\frac{\partial v^{\prime}}{\partial t}+\frac{u_{0}+u^{\prime}}{a \cos \varphi} \frac{\partial v^{\prime}}{\partial \lambda}+\frac{v^{\prime}}{a} \frac{\partial v^{\prime}}{\partial \varphi}+w^{\prime} \frac{\partial v^{\prime}}{\partial r}+\frac{2 u_{0} u^{\prime}+\left(u^{\prime}\right) 2}{a} \tan \varphi \\
\quad+\frac{v^{\prime} w^{\prime}}{a}+2 \Omega \sin \varphi u^{\prime} \\
\quad=-\frac{R}{a}\left[\frac{\partial T^{\prime}}{\partial \varphi}+\frac{T_{0}+T^{\prime}}{\rho_{0}+\rho^{\prime}} \frac{\partial\left(\rho_{0}+\rho^{\prime}\right)}{\partial \varphi}-\frac{T_{0}}{\rho_{0}} \frac{\partial \rho_{0}}{\partial \varphi}\right]-D_{\varphi} v^{\prime} \\
\quad+\frac{1}{\rho_{0}} \frac{\partial}{\partial r}\left[\left(\mu_{0}+\rho_{0} v_{e d d y}\right) \frac{\partial v^{\prime}}{\partial r}\right]-v_{R} v^{\prime} \\
\frac{\partial w^{\prime}}{\partial t} \\
\quad+\frac{u_{0}+u^{\prime}}{a \cos \varphi} \frac{\partial w^{\prime}}{\partial \lambda}+\frac{v^{\prime}}{a} \frac{\partial w^{\prime}}{\partial \varphi}+w^{\prime} \frac{\partial w^{\prime}}{\partial r} \\
\quad-\frac{2 u_{0} u^{\prime}+\left(u^{\prime}\right)^{2}+\left(v^{\prime}\right)^{2}}{a}-2 \Omega \cos \varphi u^{\prime} \\
\quad=-R\left[\frac{\partial T^{\prime}}{\partial r}+\frac{T_{0}+T^{\prime}}{\rho_{0}+\rho^{\prime}} \frac{\partial\left(\rho_{0}+\rho^{\prime}\right)}{\partial r}-\frac{T_{0}}{\rho_{0}} \frac{\partial \rho_{0}}{\partial r}\right]-D_{r} w^{\prime} \\
\quad+\frac{1}{\rho_{0}} \frac{\partial}{\partial r}\left[\left(\mu_{0}+\rho_{0} v_{e d d y}\right) \frac{\partial w^{\prime}}{\partial r}\right]-v_{R} w^{\prime}, \\
\frac{\partial \rho^{\prime}}{\partial t}+\frac{u_{0}+u^{\prime}}{a \cos \varphi} \frac{\partial \rho^{\prime}}{\partial \lambda}+\frac{v^{\prime}}{a} \frac{\partial\left(\rho_{0}+\rho^{\prime}\right)}{\partial \varphi}+w^{\prime} \frac{\partial\left(\rho_{0}+\rho^{\prime}\right)}{\partial r} \\
\quad+\left(\rho_{0}+\rho^{\prime}\right)\left(\frac{1}{a \cos \varphi} \frac{\partial u^{\prime}}{\partial \lambda}+\frac{1}{a} \frac{\partial v^{\prime}}{\partial \varphi}+\frac{\partial w^{\prime}}{\partial r}\right) \\
\quad+\left(\rho_{0}+\rho^{\prime}\right)\left(-\frac{v^{\prime}}{a} \tan \varphi+\frac{2 w^{\prime}}{a}\right)=0, \\
\frac{\partial T^{\prime}}{\partial t}+\frac{R\left(T_{0}+T^{\prime}\right)}{c_{v}}\left(\frac{1}{a \cos \varphi} \frac{\partial u^{\prime}}{\partial \lambda}+\frac{1}{a} \frac{\partial v^{\prime}}{\partial \varphi}+\frac{\partial w^{\prime}}{\partial r}-\frac{v^{\prime}}{a} \tan \varphi+\frac{2 w^{\prime}}{a}\right) \\
\quad+\frac{u_{0}+u^{\prime}}{a \cos \varphi} \frac{\partial T^{\prime}}{\partial \lambda}+\frac{v^{\prime}}{a} \frac{\partial\left(T_{0}+T^{\prime}\right)}{\partial \varphi}+w^{\prime} \frac{\partial\left(T_{0}+T^{\prime}\right)}{\partial r} \\
\quad=\frac{(\gamma-1)}{R} J^{\prime}+\frac{(\gamma-1)}{R \rho_{0}} \frac{\partial}{\partial r}\left[\left(K_{0}+\rho_{0} K_{e d d y}\right) \frac{\partial T^{\prime}}{\partial r}\right]-\alpha T^{\prime} \\
\end{array}\right.
$$

where $t$ is local time; $r(6371 \mathrm{~km} \leq r \leq 6507 \mathrm{~km}), \lambda$ $\left(0^{\circ} \leq \lambda \leq 360^{\circ}\right)$ and $\varphi\left(-90^{\circ} \leq \varphi \leq 90^{\circ}\right)$ are vertical (positive upward), zonal (positive eastward) and meridional (positive northward) coordinates, respectively; $u^{\prime}, v^{\prime}, w^{\prime}$ are the perturbation eastward, northward and vertical velocities, respectively; $T^{\prime}$ is the perturbation temperature; $u_{0}, \rho_{0}, T_{0}$ are the zonal mean wind, background density and temperature, respectively; $R=286.9821 \mathrm{~N} \cdot \mathrm{m} / \mathrm{kg} \cdot \mathrm{K}$ is the gas constant; $c_{v}=718 \mathrm{~J} / \mathrm{kg} \cdot \mathrm{K}$ is the heat capacity at constant volume; $c_{p}=c_{v}+R$ is the heat capacity at constant pressure; $\gamma=c_{p} / c_{v} ; \Omega=7.292 \times 10^{-5} \mathrm{Rad} \mathrm{s}^{-1}$ is the earth's rotation rate; $a=6371 \mathrm{~km}$ is the mean Earth radius; $\alpha$ is the Newtonian cooling coefficient; $D_{\lambda}, D_{\varphi}, D_{r}$ are the ion drag forces in zonal, meridional, and vertical directions, respectively; $v_{R}$ is the coefficient of Rayleigh friction; $J^{\prime}$ is the diurnal and semidiurnal thermotidal heating; $K_{0}$ is the molecular thermal conductivity coefficient $\left(K_{0}=0.015 T_{0}^{2 / 3} / M\right.$, where $M$ is the mean molecular weight); $\mu_{0}$ is the dynamic molecular viscosity coefficient $\left(\mu_{0}=0.266 K_{0} / R\right) ; v_{e d d y}$ is the kinematic eddy viscosity coefficient; $K_{e d d y}$ is the eddy thermal conductivity coefficient $\left(K_{e d d y}=1.36 v_{e d d y}\right)$.

It should be noted that the linear assumption is not adopted in Eqs. (1) and that all the nonlinear terms are retained. Therefore, we call Eqs. (1) fully-nonlinear formu- 
lations. When the superposition of the migrating diurnal and semidiurnal disturbances is specified as the initial disturbance, the fully nonlinear model allows the wave-wave and wave-mean flow interactions. Therefore, the effects of these nonlinear interactions on the tides and mean flow can be quantitatively studied. In this paper, our focus is the excitation of the migrating terdiurnal tide.

\subsection{Initial values}

The GSWMs, i.e. GSWM-95 (Hagan et al., 1995) and the sequential updated versions GSWM-98 (Hagan et al., 1999), GSWM-00 (Hagan et al., 2001) and GSWM-02 (Hagan and Forbes, 2002, 2003), are the most widely accepted numerical tidal models. These models have been quite successful in reproducing some observed features of the vertical, latitudinal and seasonal structures of atmospheric tides. The GSWM-00 provides an increasingly reasonable estimate of most migrating tidal characteristics in the MLT region, and its calculation results are available from the NCAR CEDAR database (http://www.hao.ucar.edu/public/research/tiso/ gswm/gswm.html); consequently, we chose the superposition of the migrating diurnal and semidiurnal disturbances based on the GSWM-00 results to be the initial disturbance for our nonlinear model. That is to say, we take the real parts of the superposition of the migrating diurnal and semidiurnal tidal disturbances from GSWM-00 steady-state solutions with respect to $t=0$ in a certain month, i.e. $f_{a 1}(\varphi, r, 0) \cos \left[\lambda+f_{p 1}(\varphi, r, 0)\right]+f_{a 2}(\varphi, r, 0) \cos [2 \lambda+$ $\left.f_{p 2}(\varphi, r, 0)\right]$ as the initial disturbances of Eqs. (1). It should be noted that in Eqs. (1), the thermotidal heating $J^{\prime}$, Newtonian cooling efficient $\alpha$, ion drag forces $\left(D_{\lambda}, D_{\varphi}\right.$ and $D_{r}$ ), kinematic eddy viscosity coefficient $v_{e d d y}$, efficient of Rayleigh friction $v_{R}$ as well as the atmospheric background state should all be the same as those specified in GSWM-00 in order to ensure that Eqs. (1) are balanced in the case of switching off nonlinear terms.

\subsection{Boundary conditions}

A periodic boundary is implied in the zonal direction. Since the GSWM-00 results are taken as the initial disturbances, the disturbance winds, temperature and density are set to zero at the geographic poles to maintain consistency with the GSWM-00, ensuring that the amplitude differences of the diurnal and semidiurnal tides between our nonlinear model results and the initial given values presented in this paper arise from nonlinearity rather than the different polar boundary conditions that are used. At the lower boundary $(z=0)$, the conditions utilized by the GSWM-00 are adopted; at the upper boundary, a simple Rayleigh-friction "sponge" layer is employed to ensure long-term stability. The damping ("sponge") layer has been carefully designed with respect to its thickness and the shape of its damping function in order to effectively damp the reflection of upward propagating waves at the upper boundary. In this study, the top boundary is set at $136 \mathrm{~km}$, and the Rayleighfriction coefficient, $\alpha_{b r}$, in units per second is chosen as

$$
\alpha_{b r}=0.001 e^{\left(\frac{z-136}{2}\right)^{8}}
$$

where $z$ is altitude in kilometers. Our numerical experiments have verified that this damping boundary scarcely has impact on the solution in the inner computational region, especially below $110 \mathrm{~km}$. The thickness of our damping layer is much thinner than that in the GSWM-00 (the top boundary is set at $\sim 250 \mathrm{~km}$ ), and the smaller height range can make our computation more efficient.

\subsection{Processing algorithm}

In order to extract the tidal components (the first, second and third harmonics) from the simulation results, a cosine function is used to fit the computational results $\left(f_{c}(\lambda, \varphi, r, t)\right)$ based on the variable $\lambda$, that is:

$$
\begin{aligned}
f_{c}(\lambda, \varphi, r, t)= & f_{0}(\varphi, r, t)+\sum_{n=1}^{3} f_{a n}(\varphi, r, t) \\
& \times \cos \left[n(\Omega t+\lambda)+f_{p n}(\varphi, r, t)\right] .
\end{aligned}
$$

Where, $n=1(2,3)$ is for the diurnal (semidiurnal, terdiurnal) component; $f_{0}(\varphi, r, t)$ is the mean flow alteration; $f_{a n}(\varphi, r, t)$ and $f_{p n}(\varphi, r, t)$ are tidal amplitude and phase, respectively.

We would like to emphasize that all the results presented in this paper are the fitted tidal amplitudes, not the instantaneous magnitudes of tidal oscillations. Therefore, our results can factually illustrate the spatial distributions of tidal structures, rather than the natural periodic oscillations of tidal waves.

\section{Nonlinear Simulation Results \\ 3.1 Terdiurnal tide}

It is well known that the GSWM-00 provides monthly results and that the migrating diurnal and semidiurnal tides show a remarkable month-to-month variation. For exhibiting the monthly characteristics of the excited turdiurnal tide, we carried out monthly nonlinear simulations. Initialized by the GSWM-00 results, our nonlinear solutions of the migrating diurnal and semidiurnal tide may deviate from the initial tidal oscillations since the nonlinear terms are switched on. Owing to the wave-wave and wave-mean flow nonlinear interactions, the diurnal and semidiurnal tidal amplitudes may vary and, more importantly, the terdiurnal tide may be excited. By fitting our nonlinear solution according to Eq. (2), we can obtain the amplitude of excited terdiurnal tide (i.e. $\left.f_{a 3}(\varphi, r, t)\right)$.

Firstly, we present the time evolution of the excited terdiurnal tidal amplitudes in the zonal wind within an integration time of 4 days (Fig. 1). Since the excited terdiurnal tide displays a similar evolution tendency of the 12month period, we present here only the evolution for October, the month with the strongest terdiurnal tide, for reasons of space. At altitudes below $80 \mathrm{~km}$, there are no appreciable terdiurnal tidal amplitudes, which may be attributed to the small diurnal and semidiurnal tidal amplitudes there. Therefore, in the following text, we only present the computational results in the height range of $80-110 \mathrm{~km}$. Figure 1 shows that the terdiurnal tide becomes more and more significant with time at the beginning, and then, after 3 days, it varies slightly. Detailed numerical analyses reveal that its amplitude variations are less than $2.5 \mathrm{~m} \mathrm{~s}^{-1}$, indicating the nonlinear model reaches a quasi-stationary state. In view of the fact that the nonlinear model remains in the quasistationary state after 3 days, we only present the results after 


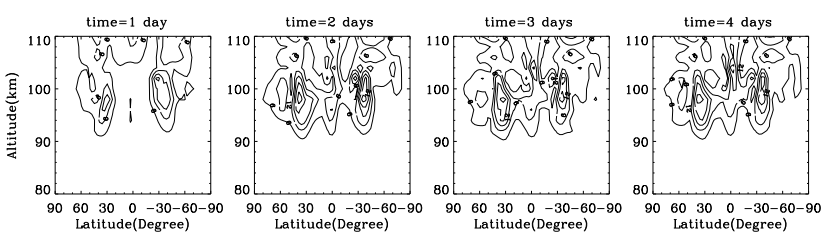

Fig. 1. Temporal evolution of the excited terdiurnal tidal amplitude in the zonal-wind component within 4 days for October. The intervals of the contours are $3 \mathrm{~m} \mathrm{~s}^{-1}$.
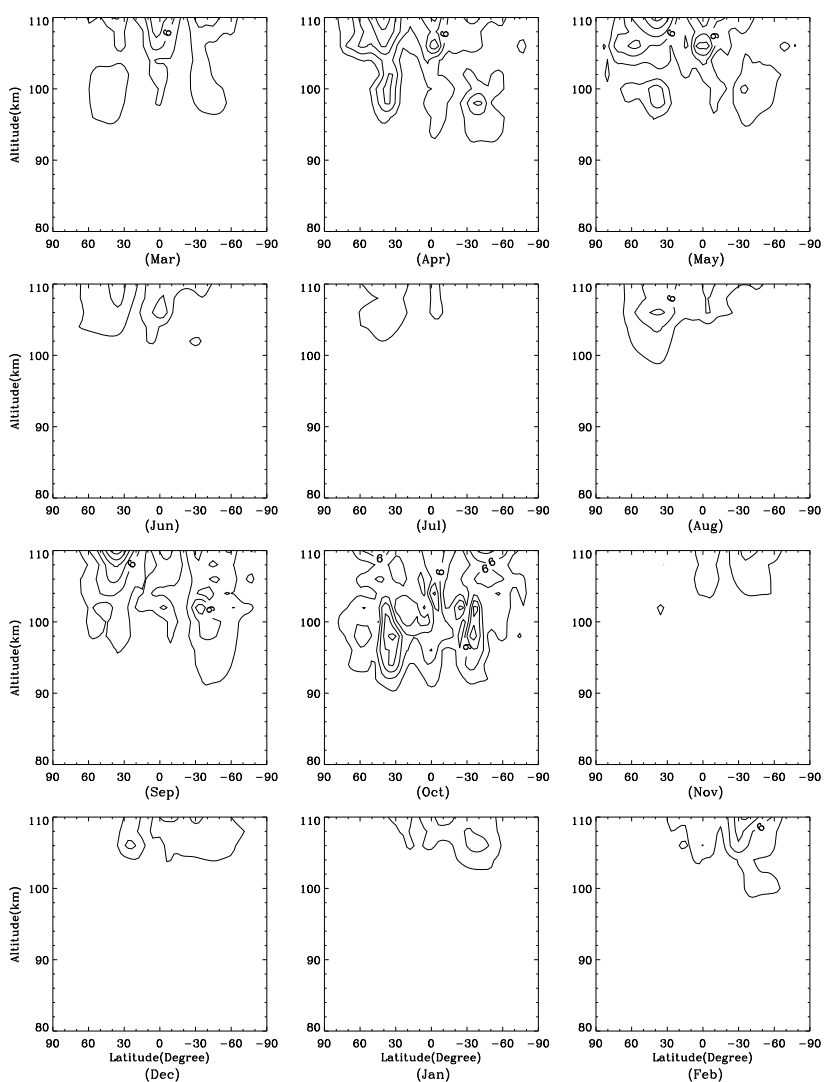

Fig. 2. Zonal-wind amplitudes of the excited terdiurnal tide for each month of the year. The intervals of the contours are $3 \mathrm{~m} \mathrm{~s}^{-1}$.

3 days to illustrate the excited terdiurnal tide.

Figures 2, 3 and 4 show the excited terdiurnal tidal amplitudes in terms of the zonal wind, meridional wind and temperature, respectively. As shown in these figures, the excited terdiurnal tide exhibits a distinct month-to-month variation, with relative maxima during equinoctial months (April, May, September and October) and minima during solstitial months (July and December). In terms of the altitude distributions, the most pronounced amplitudes appear in the height range of 90-110 km, where the GSWM-00 predicts large tidal amplitudes; in terms of the latitude distributions, the most significant amplitudes occur at the low and middle latitudes, most notably for the temperature component. For the horizontal wind components, the spatial distributions of their amplitudes are quite clearly hemispherically asymmetric, while for the temperature component, the spatial distribution is nearly hemispherically symmetric. However, it should be noted that the phases of the temperature component are asymmetric for our nonlinearly ex-
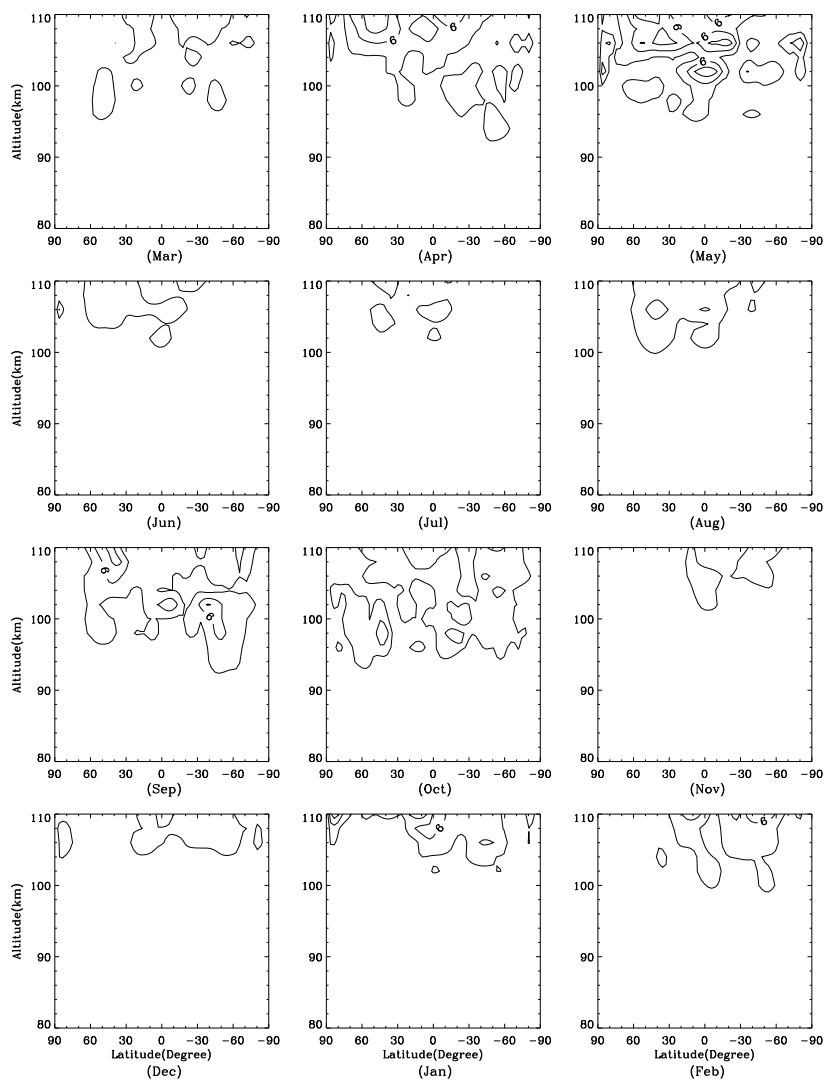

Fig. 3. Same as Fig. 2, but for meridional wind amplitudes. The intervals of the contours are $3 \mathrm{~m} \mathrm{~s}^{-1}$.

cited terdiurnal tide. For the horizontal winds, in solstitial months the tidal amplitudes are larger in the summer hemisphere than in the winter hemisphere, which is contrary to the observed terdiurnal tide. The excited terdiurnal mode is more evident in the zonal wind than in the meridional wind, and their maximum amplitudes reach 19.9 and $11.5 \mathrm{~m} \mathrm{~s}^{-1}$, respectively. For the temperature component, large amplitudes are centralized in the equator region and the largest value is $13.3 \mathrm{~K}$.

The above results indicate that the nonlinear interaction between the migrating diurnal and semidiurnal tides can evidently excite the migrating terdiurnal tide in the MLT, especially above $90 \mathrm{~km}$, and that its significant amplitudes are often accompanied by the large diurnal and semidiurnal tidal amplitudes (implying stronger nonlinear interaction). The maximum amplitude of the excited terdiurnal tide is generally much smaller than that of the diurnal or semidiurnal tide, although at some locations its amplitude can be comparable to that of the diurnal or semidiurnal tide. The excited terdiurnal tide is dominant at low and middle latitudes, where the diurnal and semidiurnal tidal amplitudes are large. In equinoctial months (April, May, September and October), the excited terdiurnal tide is very strong, while in solstitial months (July and December), it is very weak; moreover, in the winter hemisphere, it is weaker than in the summer hemisphere.

We expand the excited terdiurnal temperature disturbance for October at a prescribed height for our fitted result based on the normalized first three symmetric (i.e., (3, 

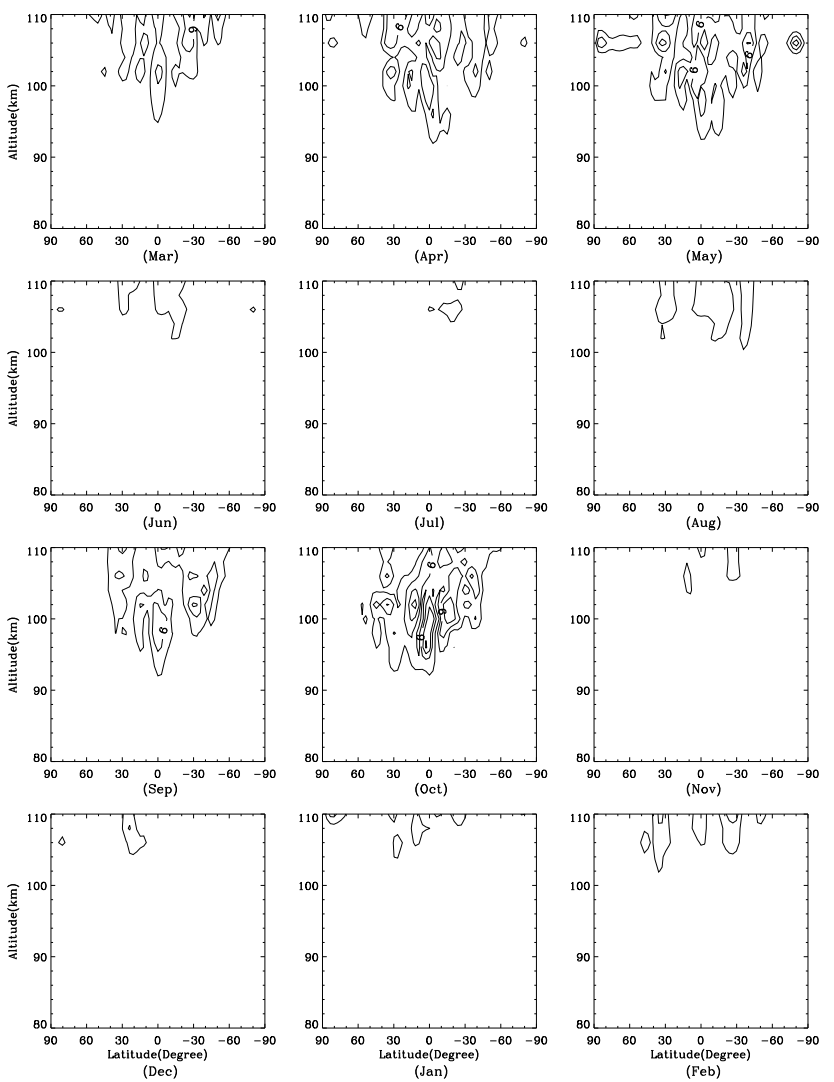

Fig. 4. Same as Fig. 2, but for temperature amplitudes. The intervals of the contours are $3 \mathrm{~K}$.

Table 1. The relative contributions of the first three symmetric $((3,3)$, $(3,5),(3,7))$ and asymmetric $((3,4),(3,6),(3,8))$ terdiurnal Hough modes for the nonlinearly generated terdiurnal temperature tide between $90-110 \mathrm{~km}$.

\begin{tabular}{rcccccc}
\hline & $(3,3)$ & $(3,5)$ & $(3,7)$ & $(3,4)$ & $(3,6)$ & $(3,8)$ \\
\hline $90 \mathrm{~km}$ & 0.563 & 0.282 & 0.105 & 0.031 & 0.012 & 0.008 \\
$92 \mathrm{~km}$ & 0.572 & 0.158 & 0.117 & 0.053 & 0.095 & 0.005 \\
$94 \mathrm{~km}$ & 0.528 & 0.196 & 0.021 & 0.087 & 0.093 & 0.074 \\
$96 \mathrm{~km}$ & 0.473 & 0.273 & 0.105 & 0.105 & 0.025 & 0.020 \\
$98 \mathrm{~km}$ & 0.504 & 0.378 & 0.017 & 0.028 & 0.049 & 0.024 \\
$100 \mathrm{~km}$ & 0.464 & 0.257 & 0.145 & 0.062 & 0.023 & 0.049 \\
$102 \mathrm{~km}$ & 0.522 & 0.158 & 0.156 & 0.062 & 0.051 & 0.051 \\
$104 \mathrm{~km}$ & 0.474 & 0.189 & 0.243 & 0.038 & 0.048 & 0.008 \\
$106 \mathrm{~km}$ & 0.478 & 0.255 & 0.117 & 0.063 & 0.034 & 0.053 \\
$108 \mathrm{~km}$ & 0.467 & 0.113 & 0.116 & 0.176 & 0.046 & 0.082 \\
$110 \mathrm{~km}$ & 0.426 & 0.307 & 0.154 & 0.056 & 0.020 & 0.036 \\
\hline
\end{tabular}

3), $(3,5),(3,7))$ and asymmetric (i.e., $(3,4),(3,6),(3,8))$ terdiurnal Hough Functions. Their relative contributions in the height range of $90-110 \mathrm{~km}$, where the excited terdiurnal tide has significant temperature amplitude, are listed in Table 1. By comparing Hough mode relative coefficients, we found that the dominant Hough mode is the $(3,3)$ mode and that the three symmetric Hough modes have a greater contribution than the three asymmetric Hough modes. The sum of relative contributions of the three asymmetric Hough modes is less than $26 \%$.
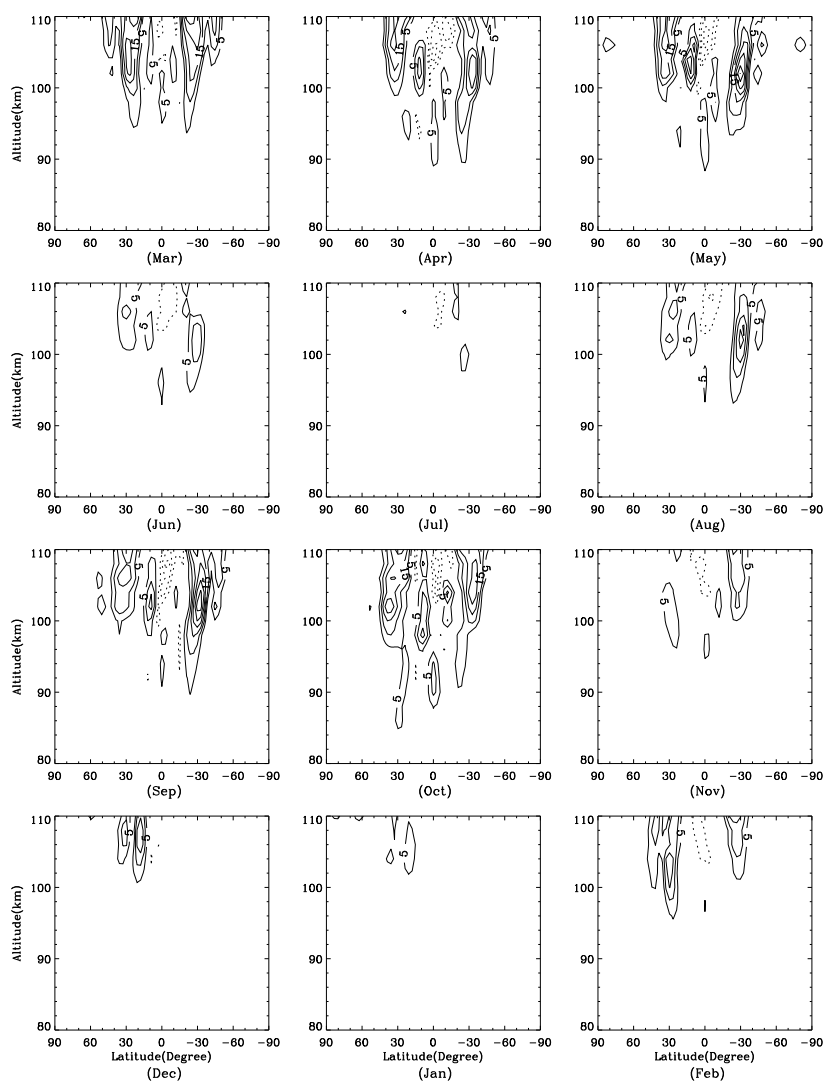

Fig. 5. Tidal variability (specified by subtracting the GSWM-00 tidal amplitudes from our nonlinear model tidal amplitudes) of the migrating diurnal tide in the temperature for each month of the year. The intervals of the contours are $5 \mathrm{~K}$. The solid and dotted curves denote the positive and negative values, respectively.

\subsection{Diurnal tidal difference}

In this subsection, we will compare the fitted diurnal tidal amplitudes from our nonlinear model with the initial given amplitudes. The amplitude differences are expressed by subtracting the initial given amplitudes from our nonlinear model amplitudes, which can be regarded as the tidal difference arising from nonlinearity (the nonlinear wave-wave and wave-mean flow interactions).

The nonlinear interaction between the diurnal and semidiurnal tides is known to be responsible not only for the variability of the terdiurnal tide but also for that of the diurnal tide (Teitelbaum et al., 1989). A secondary diurnal tide is generated by this interaction, and the fitted diurnal amplitude should be the superposition of the primary and secondary diurnal tides. Figure 5 shows the diurnal tidal difference in the temperature component after 3 days of integration time and reveals very clearly that the temperature amplitude of the diurnal tide increases in most regions. For the monthly characteristics, the diurnal tidal difference in terms of temperature displays the similar month-to-month variation as that observed in Figs. 2-5, namely, it maximizes during April, May, September and October and minimizes during solstitial months (July and January). The difference is significant at low and middle latitudes. In equinoctial months, the tidal difference is very intensive and exhibits very similar altitude-latitude distributions, while in solstitial months, the tidal difference is rather weak, being a little 

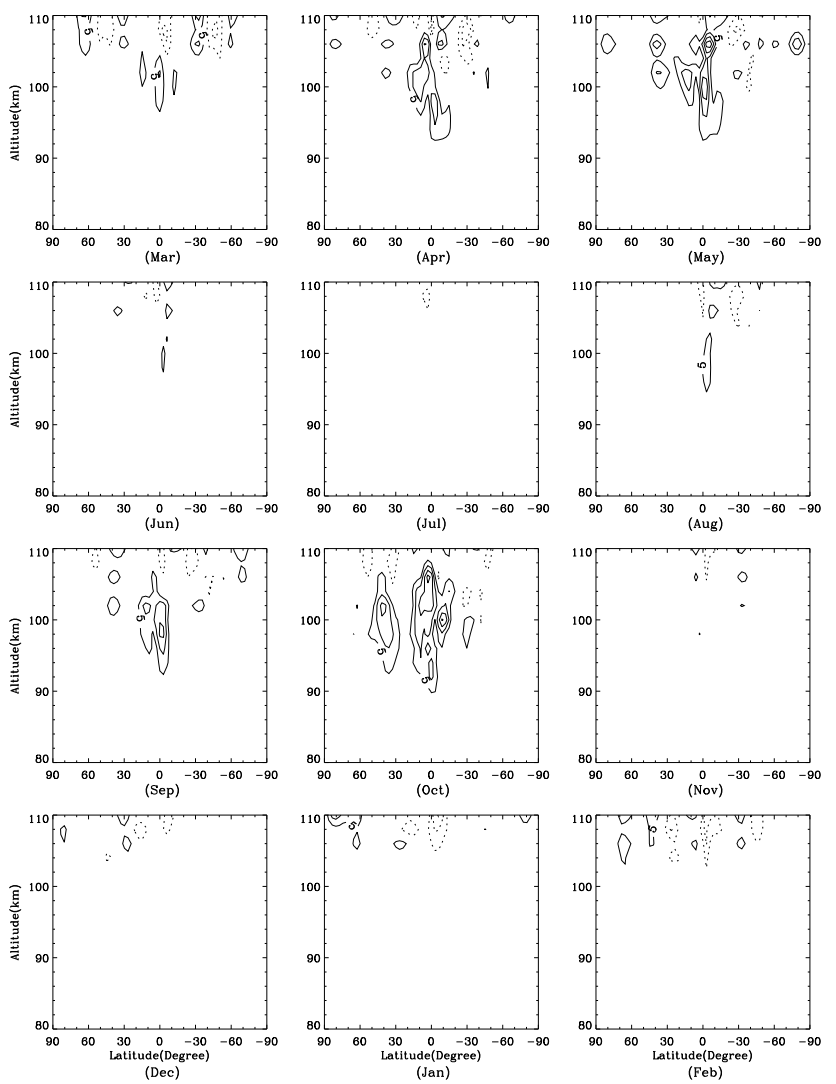

Fig. 6. Same as Fig. 5, but for the migrating semidiurnal tide. The intervals of the contours are $5 \mathrm{~K}$. The solid and dotted curves denote the positive and negative values, respectively.
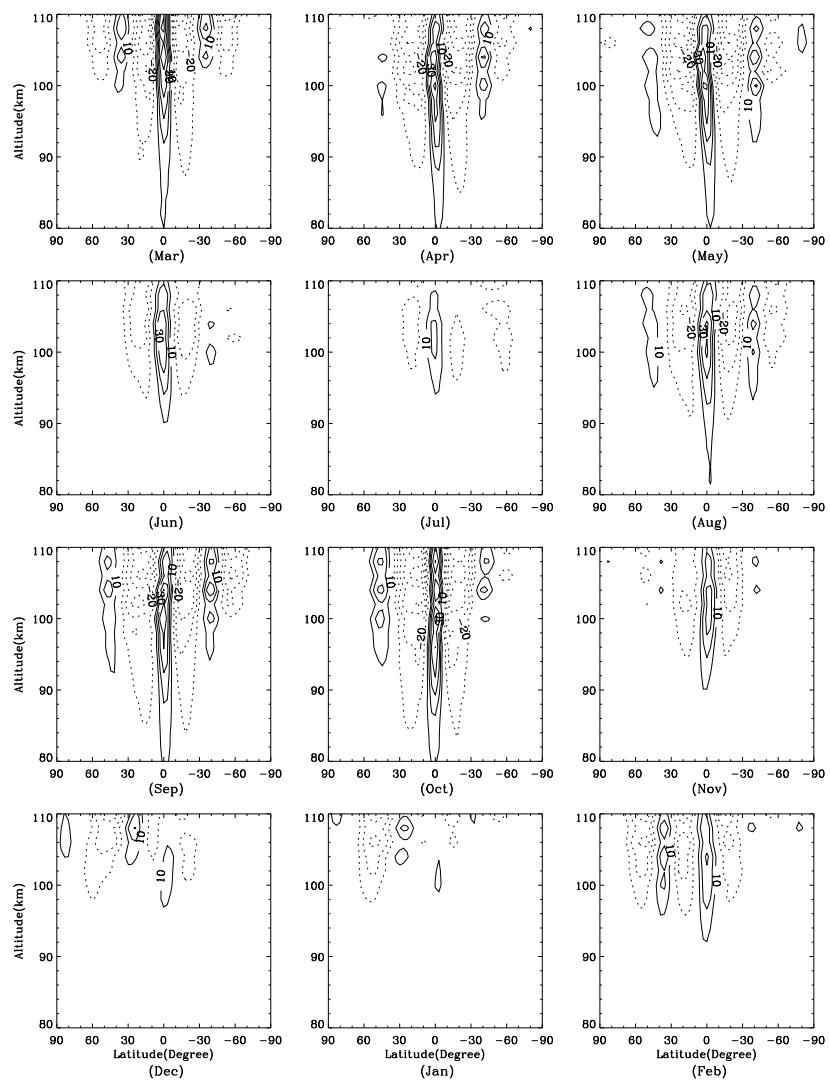

Fig. 7. Background temperature alterations for each month of the year The intervals of the contours are $5 \mathrm{~K}$. The solid and dotted curves denote the positive and negative values, respectively. stronger in the winter hemisphere than in the summer hemisphere. The largest magnitude of diurnal tidal differences in the temperature is $35.1 \mathrm{~K}$, occurring in May and at $102 \mathrm{~km}$ and $30 \mathrm{~S}$, which corresponds exactly to the area where the diurnal tidal amplitude predicted by the GSWM-00 maximizes.

It can be concluded that the wave-wave and wave-mean flow interactions can lead to notable variability in the diurnal tide in the MLT region above $90 \mathrm{~km}$, especially in equinoctial months, and should be regarded as one of the more important causes of tidal variability.

\subsection{Semidiurnal tidal difference}

The semidiurnal tidal difference arising from nonlinearity shows a monthly behavior. Figure 6 shows the semidiurnal tidal difference in terms of the temperature component after 3 days and clearly reveals that the temperature difference exhibits remarkable seasonal features: it is very noticeable in equinoctial months and rather weak in solstitial months. Similarly, the significant difference appears at low and middle latitudes and above $90 \mathrm{~km}$. During the equinoctial months, there is an evident amplitude increase in the equator region between $94-106 \mathrm{~km}$, with a maximum increase of $23.9 \mathrm{~K}$.

Although in equinoctial months, the semidiurnal tidal temperature amplitude also increases in the equator region compared with the diurnal tide, the increase is not so significant and is restricted to a smaller region and a fewer months.

Figure 6 indicates that the wave-wave and wave-mean flow interactions can intensively impact on the semidiurnal tidal structures in the MLT region above $90 \mathrm{~km}$, especially during equinoctial months.

\subsection{Background alterations}

In terms of the background alterations due to the wavemean flow interaction, we concentrate, as in the preceding sections, on the temperature component. Nonlinear interactions can induce alterations in the dynamical and thermal structures of the background atmosphere. Our nonlinear model allows us to explore quantitatively the nonlinear interactions on the monthly climatology of the background atmosphere. Fitting our nonlinear solution according to Eq. (2), we can get the time-dependent mean flow alteration. After subtracting the prescribed mean flow, we can attain the mean flow alteration. The presented background alterations are also the results of a 3-day integration time. Figure 7 presents the alterations in the background temperature for each month of the year. Some characteristics presented in previous figures can also been observed in Fig. 7, such as large magnitudes occurring above $90 \mathrm{~km}$ and at low and middle latitudes. Although the initially prescribed background temperature varies greatly with the month, the alterations in equinoctial months show the similar latitudinalaltitudinal distributions (Fig. 7). In equinoctial months, the background temperature variations show a nearly hemispherical symmetry, and their most striking feature is a tendency for the variation magnitudes to be weaker polewardly. The background is warmed up intensively at the equato- 
rial belt of $\sim 6^{\circ} \mathrm{N}$ to $\sim 6^{\circ} \mathrm{S}$ and moderately at higher latitudes greater than $\sim 40 \mathrm{~N} / \mathrm{S}$, while it is cooled down strongly at mid-latitudes, from $\sim 6^{\circ} \mathrm{N}(\mathrm{S})$ to $\sim 40^{\circ} \mathrm{N}(\mathrm{S})$. The maximum increase $(53.0 \mathrm{~K})$ and decrease $(-60.1 \mathrm{~K})$ are found in October, both of which are rather large values, while in December, January and February, the background temperature alterations are hemispherically asymmetric and the most notable magnitudes are centralized in the winter hemisphere. Figure 7 demonstrates that the wave-mean flow interaction can intensively affect the transient thermal structures of the background atmosphere in the MLT region.

In addition, background winds also vary greatly, and the maximum alterations in the zonal and meridional winds are respectively 31.2 and $12.8 \mathrm{~m} \mathrm{~s}^{-1}$ (calculations not presented here).

\section{Discussion}

Our nonlinear simulations demonstrate very clearly the altitude-latitude distributions of the amplitude of the terdiurnal tide excited by nonlinear interaction between the diurnal and semidiurnal tides and their time evolution.

Some observations (Thayaparan, 1997; Pendleton et al., 2000; Yi, 2001; Namboothiri et al., 2004) have revealed the existence of short-term tediurnal tidal variability. The more probable candidate for the variability of the terdiurnal tide is the nonlinear wave-wave interaction between diurnal and semidiurnal tides (Aso, 2003). The time evolution of the excited terdiurnal tidal amplitude presented in Fig. 1 does illustrate that the instantaneous interaction between the diurnal and semidiurnal tides can lead to strong day-to-day variability in the terdiurnal tide amplitudes. Of course, the presented simulations do not include a high degree of factual variability on short timescales since the specified heating forcing and tidal fields are seasonal or monthly averages. However, once the instantaneous conditions are specified, the instantaneous interaction effects can be displayed by our model, and the time evolution of the instantaneously generated terdiurnal tide can be exhibited.

Our simulations reveal many characteristics of the nonlinearly excited terdiurnal tide, and our results show a number of consistencies with tidal observations. For the altitude distribution, the terdiurnal tide is almost not appreciable below $85 \mathrm{~km}$, which agrees well with observations made by other investigators (Teitelbaum et al., 1989; Hall et al., 1998; Batista et al., 2004). For the latitude distribution, the pronounced terdiurnal tidal amplitudes appear at low and middle latitudes, which is also consistent with earlier observations (Teitelbaum et al., 1989; Thayaparan, 1997; Smith, 2000; Smith and Ortland, 2001). In addition, the feature of the excited terdiurnal tide revealed by our modeling that the amplitudes of its zonal wind are larger than those of its meridional wind can also be determined from tidal observations (Thayaparan, 1997; Hall et al., 1998; Smith, 2000; Smith and Ortland, 2001). Moreover, our simulations are in good accordance with the modeling work by Akmaev (2001), i.e. that the nonlinear interaction between the diurnal and semidiurnal tides make a noticeable in situ contribution to the excitation of the terdiurnal tide at 95$110 \mathrm{~km}$, especially during equinox. In fact, the pronounced nonlinearly-excited terdiurnal tide during equinox at mid- latitudes has been observed earlier (Taylor et al., 1999; Thayaparan, 1997).

However our modeling results also show some inconsistencies with observations or the results of other modeling analyses. Our simulations reveal that the excited terdiurnal tide in the zonal and meridional winds in the MLT has strong seasonal variations: in solstitial months, larger amplitudes occur in the summer hemisphere, which is contrary to some observations (Teitelbaum et al., 1989; Thayaparan, 1997; Akmaev, 2001; Smith and Ortland, 2001; Aso, 2003; Namboothiri et al., 2004). Since the observed behavior of the terdiurnal tide is mainly produced by the superposition of the solar-driven tide and the nonlinearly generated one and our work can not account for the solar-driven tide, such a discrepancy is understandable. In addition, in our work, the significant amplitudes occur at low and middle latitudes-, especially at the middle latitudes, indicating that the nonlinear interaction makes a major contribution in middle latitudes where the diurnal and semidiurnal tidal amplitudes are large; this result is not consistent with the modeling work by Smith and Ortland (2001). The calculations of these researchers indicated that the nonlinear interaction between the diurnal and semidiurnal tides was a minor contribution to the terdiurnal tide at middle latitudes. Since large diurnal and semidiurnal tidal amplitudes imply a strong nonlinear interaction, we propose that our result is the more reasonable of the two.

In our modeling approach, the terdiurnal tide generated by the nonlinear interactions among different atmospheric wave modes (tides, planetary waves and gravity waves) are not taken into consideration. In fact, some theoretical investigations (Forbes et al., 1991; Miyahara and Forbes, 1991) have revealed that these interactions can induce the terdiurnal tide but that the amplitudes are much smaller than their counterparts generated by direct heating excitation or nonlinear interaction between the diurnal and semidiurnal tides.

An essentially linear model, such as the GSWM-00, cannot present the background field alterations resulting from the nonlinear wave-mean flow interaction. Our nonlinear model can facilitate correlative studies, and the results from our simulation have displayed rather significant alterations (with maximum magnitudes of $60.1 \mathrm{~K}$ for the temperature field), suggesting that for a further understanding of the global dynamics of the MLT region, the influences of wavemean flow interaction should be seriously studied.

Finally, we should analyze the nonlinear processes involved in our nonlinear simulation in detail. Once the initial tidal disturbances - i.e. the superposition of the migrating diurnal and semidiurnal disturbances_-are prescribed, the tidal evolution will accompany complex nonlinear interactions, which has been clearly elucidated by Angelats i Coll and Forbes (2002) and Huang et al. (2007a, b). In addition to the resonant interaction between the initially given diurnal tide and semidiurnal tide, there can also be the self interaction of the diurnal tide and semidiurnal tide. If we consider that the migrating diurnal tide has a frequency (in cycles per day) of $n_{1}=1$ and a wave number of $s_{1}=1$ and that the migrating semidiurnal tide has a frequency (in cycles per day) of $n_{2}=2$ and a wave number of $s_{2}=2$, 

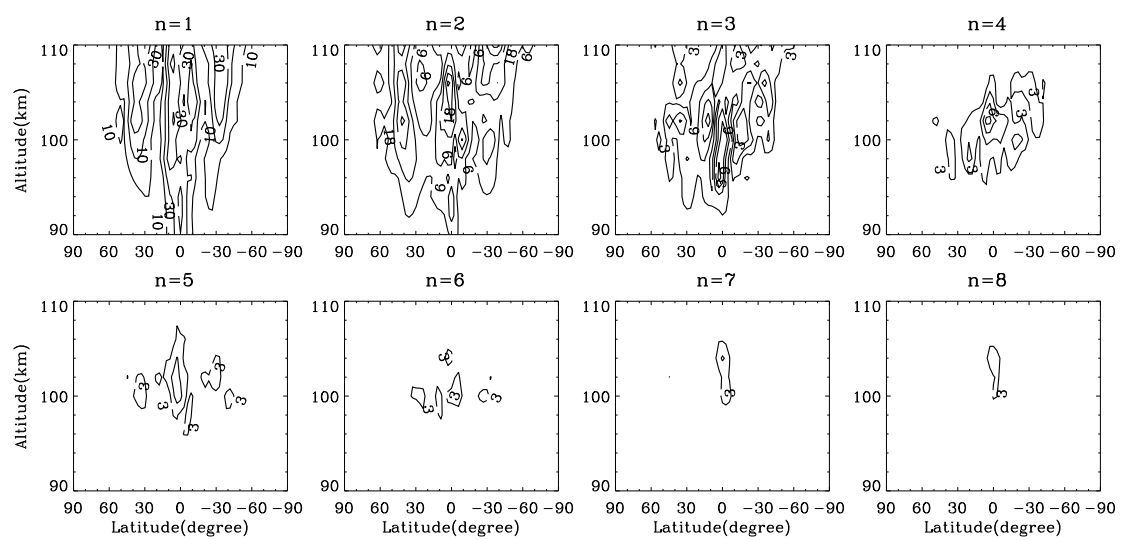

Fig. 8. Eight tidal component amplitudes in the temperature for October. For the 24-h and 12-h components, the minimum value and intervals of the contour are respectively $10 \mathrm{~K}$ and $6 \mathrm{~K}$, while for the other components, the minimum values and intervals of the contours are $3 \mathrm{~K}$.

the former will excite the terdiurnal tide with a frequencywave number pair $(3,3)$, and the latter will excite the 12-h and 24-h tides with frequency-wave number pairs $(2,2)$ and $(4,4)$, respectively. Subsequently, the excited tides may resonantly interact with the original tides to create more tidal components; for example, the interaction between the terdiurnal and diurnal tides will create the two waves with frequency-wave number pairs $(4,4)$ and $(2,2)$, and the interaction between the terdiurnal and semidiurnal tides will create the two waves with frequency-wave number pairs (5, $5)$ and $(1,1)$. These cascade nonlinear interactions can generate many migrating tidal components and many new diurnal and semidiurnal tidal parts, which will further alter the diurnal and semidiurnal tidal structure as well as the mean flow/tidal interaction. Here, we want to compare the amplitudes of different tidal components in our nonlinear solution. Since the generated tides are all migrating components, we can analyze the tide components in a spatial domain instead of in a temporal domain. In order to extract the tidal components (the first eighth harmonics) from our nonlinear simulation results, we used a cosine function to fit the computational results $\left(f_{c}(\lambda, \varphi, r, t)\right)$ based on the variable $\lambda$, that is:

$$
\begin{aligned}
f_{c}(\lambda, \varphi, r, t)= & f_{0}(\varphi, r, t)+\sum_{n=1,2, \ldots, 8} f_{a n}(\varphi, r, t) \\
& \times \cos \left[n(\Omega t+\lambda)+f_{p n}(\varphi, r, t)\right]
\end{aligned}
$$

where, $n=1(2, \ldots, 8)$ is for the diurnal (semidiurnal, $\ldots, 3$-h) component; $f_{0}(\varphi, r, t)$ is the mean flow alteration; $f_{a n}(\varphi, r, t)$ and $f_{p n}(\varphi, r, t)$ are tidal amplitude and phase, respectively. Figure 8 presents the temperature amplitude structures of the above eighth tidal components deduced from our nonlinear simulation result for October. It can be clearly seen that apparent 8-h, 6-h and 4.8-h tides are excited by nonlinear interactions and that the 8 -h component is the most significant. Therefore, we can conclude that the tidal amplitude differences presented here are the combination effects of wave-mean flow and wave-wave interactions and that the background changes arise from the interactions between the background atmosphere and each tidal component, including the initial given tidal components and the nonlinearly generated tidal components.

\section{Conclusions}

In this paper, we develop a numerical tidal model based on the fully-nonlinear Navier Stokes equations in spherical coordinates to explore the characteristics of the terdiurnal tide excited by nonlinear interaction between the diurnal and semidiurnal tides. The superposition of the migrating diurnal and semidiurnal tidal solutions from the GSWM00 (Global Scale Wave Model 2000) is taken as the initial disturbance for this nonlinear model. Once the model is initialized, the tidal components and mean flow are allowed to nonlinearly interact with each other.

Our simulations show that the migrating terdiurnal tide can be significantly excited by the nonlinear interaction between the diurnal and semidiurnal tides in the MLT region, especially above $90 \mathrm{~km}$, and that it can have pronounced amplitudes (wind speeds over $15 \mathrm{~m} \mathrm{~s}^{-1}$ and temperature over $10 \mathrm{~K}$ ) in the lower thermosphere $(90-110 \mathrm{~km})$. In addition, its amplitudes vary strongly with season and maximize during equinoctial months at low and middle latitudes, and its zonal wind component is larger than the meridional wind component.

Concurrently with the generation of the terdiurnal tide, the diurnal and semidiurnal tides exhibit evident variations, indicating that the wave-wave and wave-mean flow interactions are the more important causes of tidal variability. Possibly due to the generation of the secondary diurnal tide, the temperature amplitude of the diurnal tide is significantly increased in most regions where notable tidal variation occurs. Additionally, our calculations also illustrate the great variation in the background atmosphere and reveal the intensive impact of the mean flow/tidal interaction on the global transient dynamical and thermal structures, implying that this interaction should be comprehensively taken into consideration when describing global atmospheric dynamic and thermal structures in the MLT region.

Acknowledgments. This work was jointly supported by the National Natural Science Foundation of China (through grants 40504018, 40336054 and 40575020), the Program for New Century Excellent Talents in University of China, the Cultivation Fund of the Key Scientific and Technical Innovation Project, Ministry of Education of China (No. 2004-295), PCSIRT, the Fund of the Key Scientific and Technical Project, Ministry of Education of China (NO: 03110), and the Opening Foundation of SOA Key Laboratory for Polar Science (KP2005010). 


\section{References}

Akmaev, R. A., Seasonal variations of the terdiurnal tide in the. mesosphere and lower thermosphere: A model study, Geophys. Res. Lett., 28, 3817-3820, 2001.

Angelats i Coll, M. and J. M. Forbes, Nonlinear interactions in the upper atmosphere: the $s=1$ and $s=3$ nonmigrating semidiurnal tides, $J$. Geophys. Res., 107(A8), 1157, doi:10.1029/2001JA900179, 2002.

Aso, T., An overview of the terdiurnal tide observed by polar radars and optics, Adv. Polar Upper Atmos. Res., 17, 167-176, 2003.

Batista, P. P., B. R. Clemesha, A. S. Tokumoto, and L. M. Lima, Structure of the mean winds and tides in the meteor region over Cachoeira Paulista, Brazil $\left(22.7^{\circ} \mathrm{S}, 45^{\circ} \mathrm{W}\right)$ and its comparison with models, J. Atmos. Sol-Terr. Phys., 66, 623-636, 2004.

Canuto, C., M. Y. Hussaini, A. Quarteroni, and T. A. Zang, Spectral methods in fluid dynamics, Springer-Verlag, New York, London, 1988.

Forbes, J. M., J. Gu, and S. Miyahara, On the interactions between gravity waves and the diurnal propagating tides, Planet. Space Sci., 39, 12491257, 1991.

Hagan, M. E. and J. M. Forbes, Migrating and nonmigrating diurnal tides in the middle and upper atmosphere excited by tropospheric latent heat release, J. Geophys. Res., 107(D24), 4754, doi:10.1029/2001JD001236, 2002.

Hagan, M. E. and J. M. Forbes, Migrating and nonmigrating semidiurnal tides in the upper atmosphere excited by tropospheric latent heat release, J. Geophys. Res., 108(A2), 1062, doi:10.1029/2002JA009466, 2003.

Hagan, M. E., J. M. Forbes, and F. Vial, On modeling migrating solar tides, Geophys. Res. Lett., 22, 893-896, 1995.

Hagan, M. E., M. D. Burrage, J. M. Forbes, et al., GSWM-98: results for migrating solar tides, J. Geophys. Res., 104, 6813-6827, 1999.

Hagan, M. E., R. G. Roble, and J. Hackney, Migrating thermospheric tides, J. Geophys. Res., 106, 12,739-12,752, 2001.

Hall, C. M., A. H. Manson, and C. E. Meek, Spectral characteristics of spring arctic mesosphere dynamics, Ann. Geophys., 16, 1607-1618, 1998.

Huang, C. M., S. D. Zhang, and F. Yi, A numerical study of the impact of nonlinearity on the amplitude of the migrating diurnal tide, J. Atmos. Sol-Terr. Phys., 69, 631-648, 2007a.

Huang, C. M., S. D. Zhang, and F. Yi, A numerical study on the impact of nonlinear interactions on the amplitude of the migrating semidiurnal tide, Ann. Geophys., 2007b (in press).

Miyahara, S. and J. M. Forbes, Interactions between gravity waves and the diurnal tide in the mesosphere and lower thermosphere, J. Meteorol. Soc. Jpn., 69, 523-531, 1991.

Namboothiri, S. P., P. Kishore, Y. Murayama, et al., MF radar observations of terdiurnal tide in the mesosphere and lower thermosphere at Wakkanai $\left(45.4^{\circ} \mathrm{N}, 141.7^{\circ} \mathrm{E}\right)$, Japan, J. Atmos. Sol-Terr. Phys., 66, 241250, 2004.

Pendleton, W. R., M. J. Taylor, and L. C. Gardner, Terdiurnal oscillations in $\mathrm{OH}$ Meinel rotational temperatures for fall conditions at northern midlatitude sites, Geophys. Res. Lett., 27, 1799-1802, 2000.

Smith, A. K., Structure of the terdiurnal tide at $95 \mathrm{~km}$, Geophys. Res. Lett., 27, 177-180, 2000.

Smith, A. K. and D. A. Ortland, Modeling and analysis of the structure and generation of the terdiurnal tide, J. Atmos. Sci., 58, 3116-3134, 2001.

Taylor, M. J., W. R. Pendleton, Jr., C. S. Gardner, and R. J. States, Comparison of terdiurnal tidal oscillations in mesospheric $\mathrm{OH}$ rotational temperature and $\mathrm{Na}$ lidar temperature measurements at mid-latitudes for fall/spring conditions, Earth Planets Space, 51, 877-885, 1999.

Teitelbaum, H., F. Vial, A. H. Mason, et al., Non-linear interaction between the diurnal and semidiurnal tides: terdiurnal and diurnal secondary waves, J. Atmos. Terr. Phys., 51, 627-634, 1989.

Thayaparan, T., The terdiurnal tide in the mesosphere and lower thermosphere over London, Canada $\left(43^{\circ} \mathrm{N}, 81^{\circ} \mathrm{W}\right)$, J. Geophys. Res., 102, 21,695-21,708, 1997.

Wu, Q., N. J. Mitchell, T. L. Killeen, S. C. Solomon, and P. T. Younger, A high-latitude 8-hour wave in the mesosphere and lower thermosphere, J. Geophys. Res., 110, A09301, doi:10.1029/2005JA011024, 2005.

Yi, F., Short-term variability and temporary structures of tides and mean wind in the polar summer mesosphere, J. Atmos. Sol-Terr. Phys., 63, 749-757, 2001.

Zhang, S. D., F. Yi, and X. Hu, MF radar observation of mean wind and tides of winter mesopause $(80-98 \mathrm{~km})$ region over Wuhan $\left(30^{\circ} \mathrm{N}\right.$, $114^{\circ}$ E), J. Atmos. Sol-Terr. Phys., 66, 15-25, 2004.

C. M. Huang, S. D. Zhang (e-mail: zsd@whu.edu.cn), and F. Yi 